T lymphocytes can be independent of tumour MHC/ICAM-1 expression.

In many inflammatory situations, such as allograft rejection, delayed type hypersensitivity responses and various allergic diseases, ${ }^{7}$ increased expression of MHC (particularly class II) and ICAM-1 is thought to be related directly to cytokines secreted from the large numbers of activated mononuclear cells reacting to foreign antigens. Inflammatory responses often occur in cancers, but the nature of the stimulus is unclear. In some situations responses to tumour associated antigens may be occurring; in others the response may be due to necrosis or to the breakdown of the mucosal barrier, allowing leakage of luminal antigens. What is clear is that, whatever the nature of the stimulus, there is some form of functional disregulation of the inflammatory response in oesophageal carcinoma (as has also been seen in other carcinomas such as those of the lung ${ }^{8}$ and cervix ${ }^{9}$ ) as $\mathrm{MHC} / \mathrm{ICAM}-1$ expression is not related to $\mathrm{T}$ lymphocyte numbers or activation. It is possible that the neoplastic cells of both oesophageal squamous cell carcinomas and adenocarcinomas might produce immunosuppressive factors, such as transforming growth factor- $\beta 1$, which antagonise or inhibit the production or effect of inflammatory cytokines such as interferon- $\gamma$. The elucidation of the mechanisms contributing to the dis- regulation of immune cells such as $\mathrm{T}$ lymphocytes is an important challenge, the solution of which might permit more effective treatment of these aggressive tumours.

JCR and SID are funded by the Oesophageal Cancer Research Appeal (OCRA), Birmingham.

We are most grateful to Ms L Billingham of the University of Birmingham CRC Institute for Cancer Studies for assistance with statistical analysis. Miss $\mathrm{K}$ Jenner and Mr G Mannion contributed valuable technical and photographic skills, respectively.

1 Matthews HR, Waterhouse JAH, Powell J, McConkey CC Robertson JE (eds). Overall survival. In: Clinical cancer monographs. Vol 1. Cancer of the oesophagus. London: Macmonographs. Vol 1.

2 Vesalainen S, Lipponen P, Talja M, Syrjanen K. Histological grade, perineural infiltration, tumour infiltrating lymphocytes and apoptosis as determinants of long-term prognosis in prostatic adenocarcinoma. Eur $\mathcal{F}$ Cancer 1994;30A 1797-803.

3 Garrido F, Cabrerra T, Concha A, Glew S, Ruiz-Cabello F, Stern PL. Natural history of HLA expression during tumour development. Immunol Today 1993;14:491-9.

4 Johnson JP. The role of ICAM-1 in tumour development. Chem Immunol 1991;50:143-63.

5 Rockett JC, Damton SJ, Crocker J, Matthews HR, Morris A. Expression of HLA-ABC, HLA-DR and intercellula adhesion molecule-1 in oesophageal carcinoma. $f$ Clin Pathol 1995;48:539-44.

6 Nouri A, Hussain R, Oliver R, Handy A, Bartkova I, Bodmer $\mathrm{J}$. Immunological paradox in testicular tumours - the presence of a large number of activated T-cells despite the complete absence of MHC antigens. Eur $\mathcal{F}$ Cancer 1993; 29A:1895-9.

7 Morris A, Hewitt C, Young S. The major histocompatibility complex: its genes and their roles in antigen presentation. Mol Aspects Med 1994;15:414-15.

8 Nonomura A, Mizukami Y, Shimizu J, Hayashi Y, Murakam $S$, Watanabe Y, et al. Simultaneous detection of intercellular S, Watanabe Y, et al. Simultaneous detection of intercellular adhesion molecule-1 (CD54) and carcinoembryonic an-
tigen in lung adenocarcinoma. Mod Pathol 1994;7:155-60. tigen in lung adenocarcinoma. Mod Pathol 1994;7:155-60.
Glew A, Duggan-Keen M, Cabrera T, Stern P. HLA class II antigen expression in human papilloma virus-associated cervical cancer. Cancer Res 1992;52:4009-16.

\title{
Sudden death due to a glial cyst of the pineal gland
}

\author{
C M Milroy, C L Smith
}

Department of

Forensic Pathology,

University of Sheffield,

Sheffield

C M Milroy

Department of

Neuropathology, Royal

Hallamshire Hospital,

Sheffield

C L Smith

Correspondence to: Dr C M Milroy, Senior Lecturer in Forensic Pathology, University of Sheffield, The Medico-Legal Sheffield S3 7ES.

Accepted for publication

18 October 1995

\begin{abstract}
Asymptomatic cysts of the pineal gland are found frequently by radiological examination of the brain or at postmortem examination. Symptomatic cysts are rare, and may require surgical intervention. Sudden death due to a cystic lesion of the pineal gland is very rare. A case of a 22 year old man who collapsed and died unexpectedly is reported. Postmortem examination revealed a glial cyst of the pineal gland and evidence of chronic obstructive hydrocephalus. Deaths from colloid cysts and pineal gland cysts are rare, but should be considered where no other cause of death is evident, especially with a history of headaches. Their small size, and their possible rupture on dissection can make them difficult to detect if a careful examination is not undertaken.

(f Clin Pathol 1996;49:267-269)
\end{abstract}

Keywords: pineal gland, cyst, postmortem examination.
Sudden death due to a colloid cyst of the third ventricle, though rare, is well recognised in both adults and children. ${ }^{12}$ Asymptomatic cystic lesions of the pineal gland are quite common $^{34}$ but symptomatic lesions are very rare. ${ }^{5}$ We report the sudden death of a young man due to a glial cyst of the pineal gland.

\section{Case report}

A 22 year old white man collapsed at a disco. He had been engaged in a punching game with a friend which involved hitting each other in turn in the shoulder area. Having finished the game he collapsed. Vigorous resuscitation was commenced, but this was unsuccessful.

At postmortem examination, no significant external injuries were present. In particular, no bruising or other injury was present in the shoulder or chest area. Internal examination, including full microscopy, did not reveal any abnormality in any organ system other than the 


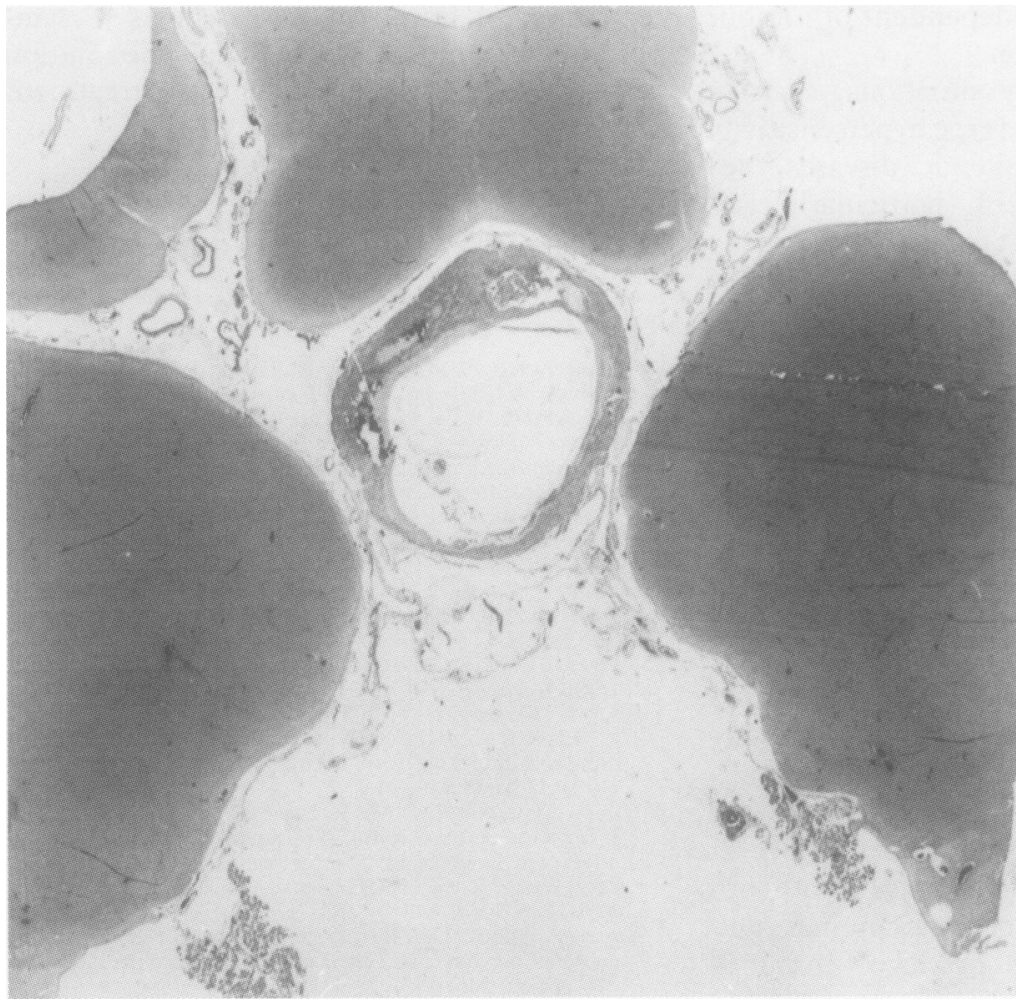

Figure 1 Pineal gland cyst lying adjacent to the midbrain.

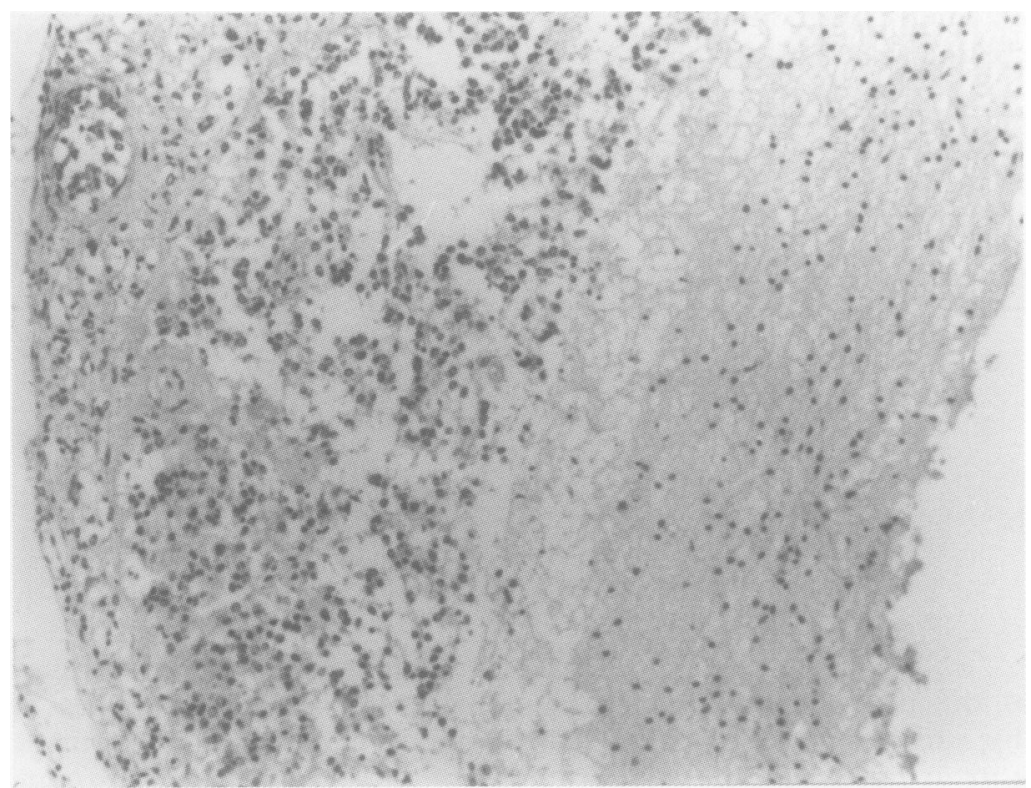

Figure 2 Section of cyst wall showing inner layer of glial tissue and outer layer of pineal tissue.
Microscopic examination showed the lesion to be a glial cyst within the pineal gland. The wall of the cyst consisted of an inner layer of glial tissue, containing some prominent Rosenthal fibres, surrounded by a zone of pineal tissue, which contained several smaller cystic areas adjacent to the main cyst. No epithelial or ependymal lining was present. Areas of calcification were present, but no evidence of recent or previous haemorrhage was found (fig 2 ). There was a space lined by choroidal epithelium above the gland, which related to the suprapineal recess of the third ventricle. Examination of the lateral ventricles showed several areas of "ependymitis", consistent with previous episodes of ventricular dilatation.

In view of the pathological findings death was ascribed to the glial cyst of the pineal gland.

\section{Discussion}

Sudden death due to a colloid cyst of the third ventricle is well recognised. These are small, histologically benign neuroepithelial lesions. They are normally 1 to $2 \mathrm{~cm}$ in diameter and are positioned in or near the foramina of Munro. In this position they can obstruct the flow of cerebrospinal fluid. This may cause raised intracranial pressure and acute hydrocephalus. Most cases show evidence of chronic obstructive hydrocephalus. Symptomology includes headache, nausea, lethargy, prostration, coma, and death. They occur in both adults and children.

A variety of neoplasms and cystic lesions may arise in the pineal gland. ${ }^{5}$ These include germinomas, teratomas, pineoblastomas, pineocytomas, astrocytomas, and melanomas. Cystic lesions include epidermoid cysts, dermoid, arachnoid, and glial cysts. Small glial cysts are commonly identified by modern imaging techniques and at necropsy. Symptomatic glial cysts are rare. In 1989, Klein and Rubenstein ${ }^{5}$ reported seven cases and reviewed the literature. Reported cases occurred in patients aged between three and 56 years. They presented with headaches, sensory cerebellar and corticospinal disturbances, Parinaud syndrome, and loss of consciousness. The headaches were believed to be caused by acute obstructive hydrocephalus. Some patients had emotional disturbances. Endocrine effects were rare. The cysts varied in size from 0.7 to $3 \mathrm{~cm}$ in diameter.

In a review of 53 patients with non-neoplastic brain. Toxicological analysis revealed a blood ethanol of $164 \mathrm{mg} / 100 \mathrm{ml}$ and a urine ethanol level of $184 \mathrm{mg} / 100 \mathrm{ml}$. A full drug screen, including screening by gas chromatography/ mass spectroscopy, was otherwise negative.

\section{Neuropathology}

The brain, which weighed $1600 \mathrm{~g}$, was generally swollen. A cystic lesion was noted posterior inferior to the third ventricle, extending posteriorly to lie immediately above the midbrain. This lesion was $1.2 \mathrm{~cm}$ in diameter (fig 1 ). The ventricular system did not appear to be dilatated. cysts of the pineal gland, Fetell et at found five cases with obstructive hydrocephalus. These cysts were all over $2.0 \mathrm{~cm}$ in diameter. Fain et $a l^{7}$ reported 24 patients with large glial cysts of the pineal gland, identified by computed tomography or magnetic resonance imaging. Twenty cases were symptomatic. The cysts varied in size from 0.8 to $3.0 \mathrm{~cm}$ in diameter. Eight patients had obstructive hydrocephalus.

One fatality due to a glial cyst of the pineal gland has been reported by Richardson and Hirsch. ${ }^{8}$ This case involved a 20 year old woman who was found dead at home unexpectedly. She was found to have bled into a glial cyst, which was $1.4 \mathrm{~cm}$ in diameter. The 
cyst wall contained a microscopic vascular malformation. A previous episode of syncope was attributed to a previous episode of bleeding, as shown by the presence of haemosiderin. The authors postulated that the cyst pressed on the midbrain, interfering with the function of the reticular formation.

A $1.2 \mathrm{~cm}$ diameter glial cyst was present in the case reported here. Microscopic examination of the lateral ventricle showed features consistent with previous ventricular dilatation. The cyst size is within the range known to cause symptoms and even death. The history of headaches over the previous day suggest the cyst was causing acute obstruction to the flow of cerebrospinal fluid. Intermittent headaches are well recognised in patients with colloid cysts, with the cysts acting as a ball valve.

Deaths from colloid cysts and pineal gland cysts are rare, but should be considered where no other cause of death is evident, especially with a history of headaches. Their small size, and their possible rupture on dissection can make them difficult to detect if a careful examination is not undertaken.

1 Leestma JA, Konakci Y. Sudden unexpected death caused by neuro-epithelial (colloid) cyst of the third ventricle. $\mathcal{f}$ Forensic Sci 1981;26:486-91.

2 Byard RW, Moore L. Sudden death in childhood due to a colloid cyst of the third ventricle. $\mathcal{f}$ Forensic Sci 1993;38: 210-13.

3 Golzarian J, Baleriaux D, Bank WO, Matos C, FlamentDurand J. Pineal cyst: normal or pathological. Neuroradiology 1993;35:151-3.

4 Di Costanzo A, Tedeschi G, Golia F, Morrone R, Bonavita V. Pineal cysts: an incidental finding? $\mathcal{F}$ Neurol Neursurg
Psychiatry 1993;56:207-8.

5 Klein P, Rubenstein LJ. Benign symptomatic glial cysts of the pineal gland: a report of seven cases and review of the literature. F Neurol Neurosurg Psychiatry 1989;52:991-5.

6 Fetell MR, Bruce JN, Burke AM, Cross DT, Torres RA, Powers JM, et al. Non-neoplastic pineal cysts. Neurology 1991;41:1034-40.

7 Fain JS, Tomlinson FH, Scheithauer BW, Fletcher GP, Kelly PJ, Miller GM. Symptomatic glial cysts of the pineal gland. f Neurosurg 1994;80:454-60.

8 Richardson JK, Hirsch CS. Sudden, unexpected death due to "pineal apoplexy". Am $₹$ Forensic Med Pathol 1986;7: to "p. 